\title{
Überlegungen zu den Motiven für die Umwandlung des Benediktinerklosters Ellwangen in ein Säkularkanonikerstift im Vorfeld des Fürstenkriegs 1459/1460
}

\author{
Von Brigitte Oberle
}

Die Umwandlung der Fürstabtei St. Vitus in Ellwangen in ein Säkularkanonikerstift 1460" ist - nach St. Alban vor Mainz 1419 - der zweite Fall eines exklusiv adligen und stiftsmäßig lebenden Benediktinerklosters, das seine von Reformansinnen unterschiedlicher Provenienz in Frage gestellte Lebensweise durch den Wechsel der Rechtsform legitimieren und dauerhaft aufrechterhalten konnte ${ }^{1}$.

* Der hier wiedergegebene Vortrag wurde bei der Jahrestagung der Kommission für geschichtliche Landeskunde in Baden-Württemberg am 1. Juli 2016 in Ellwangen gehalten. Die Vortragsform wurde beibehalten, der wissenschaftliche Apparat ergänzt.

1 Grundlegend zur Umwandlung Ellwangens ist Joseph ZELLER, Die Umwandlung des Benediktinerklosters Ellwangen in ein weltliches Chorherrnstift (1460) und die kirchliche Verfassung des Stifts. Texte und Darstellung (Württembergische Geschichtsquellen, Bd.10), Stuttgart 1910; zur Umwandlung St. Albans Reinhard Schmid, Die Abtei St. Alban vor Mainz im hohen und späten Mittelalter. Geschichte, Verfassung und Besitz eines Klosters im Spannungsfeld zwischen Erzbischof, Stadt, Kurie und Reich (Beiträge zur Geschichte der Stadt Mainz, Bd.30), Mainz 1996. - Hans Pfeifer führt die Umwandlung St. Leodegars in Luzern 1455 als zweiten Fall auf, vgl. Hans Pfeifer, Vom Benediktinerkloster Ellwangen zum weltlichen Chorherrenstift (1460), in: Ellwanger Jahrbuch 31 (1985/86) S. 53-66, hier S. 53; St. Leodegar wird auch von Peter Moraw, der in seiner Typologie von Stiftkirchen die Umwandlungen des 15. und 16. Jahrhunderts als eigenen Typus definiert, in seiner Aufzählung genannt, vgl. Peter Moraw, Über Typologie, Chronologie und Geographie der Stiftskirche im deutschen Mittelalter, in: Untersuchungen zu Kloster und Stift (Veröffentlichungen des Max-Planck-Instituts für Geschichte, Bd.68; Studien zur Germania Sacra, Bd.14), hg. vom Max-Planck-Institut für Geschichte, Göttingen 1980, S.9-37, hier S. 19. Allerdings war der Konvent dort nicht exklusiv adlig, vgl. André Heinzer, Pfründen, Herrschaft, Gottesdienst. Lebenswelten der Mönche und Weltgeistlichen am Kloster und Kollegiatstift St. Leodegar in Luzern zwischen 1291 und 1550 (Luzerner Historische Veröffentlichungen, Bd.45), Luzern 2014, S. 95 f., während die Aufrechterhaltung des Adelsprivilegs für die anderen Klöster der zentrale Konfliktpunkt war, vgl. Alfred Wendenorst, Der Adel und die Benediktinerklöster im späten Mittelalter, in: Consuetudines Monasticae. Eine Festgabe für Kassius Hallinger aus Anlass seines 70. Geburtstages (Studia Anselmia, Bd. 85), hg. von Joachim Fridolin Angerer/Josef Lenzenweger, Rom 1982, S.333-353, hier S. 334. 
Dabei erfolgte die Umwandlung Ellwangens recht unvermittelt: Noch Anfang Oktober 1459 musste der Konvent einem Schiedsspruch zu Sparmaßnahmen zur finanziellen Sanierung und dem Aufstellen von Reformstatuten zustimmen, der von Personen im württembergischen Umfeld gesprochen wurde ${ }^{2}$. Dieser Vorgang steht in einer ganzen Reihe vorheriger Reformversuche, die vom Schirmer des Klosters, Graf Ulrich V. von Württemberg, zum Teil im Zusammenwirken mit dem Augsburger Bischof und Kardinal Peter von Schaumberg erfolgten ${ }^{3}$. Jedoch nur wenige Monate später, am 2. April 1460, wurde die Ellwanger Benediktinerabtei vom Kardinal und Augsburger Bischof Peter von Schaumberg nach Genehmigung durch Papst Pius II. in ein Säkularkanonikerstift umgewandelt ${ }^{4}$. Die Bulle räumte Graf Ulrich V. das Präsentationsrecht auf die nächsten zwei freiwerdenden Pfründen ein ${ }^{5}$. Markgraf Albrecht Achilles von Brandenburg hatte sich persönlich durch eine Reise nach Mantua zum Papst für die Umwandlung verwandt und brachte die am 14. Januar 1460 ausgestellte Bulle mit hoher Wahrscheinlichkeit selbst nach Ellwangen ${ }^{6}$.

In der Forschung fallen zur Interpretation dieser Vorgänge immer wieder zwei Stichworte: „Schweigen“ und „Rücksicht“. Das „Schweigen der Quellen“ betreffe vor allem die Haltung Graf Ulrichs V.?. Zwar spreche das Präsentationsrecht, das ihm eingeräumt worden war, für eine wie auch immer geartete Zustimmung zur Umwandlung, aber deren Ausmaß wird höchst unterschiedlich eingeschätzt ${ }^{8}$. Unklar bleiben nicht nur der Grad der Akzeptanz und des Mitwirkens Ulrichs an der Umwandlung, sondern auch die Gründe für die Änderung seiner Haltung. Als allgemeines Motiv für den Sinneswandel von Reformstreben zu Reformverhinderung bei Graf Ulrich V. und Kardinal Peter werden die Rücksicht auf die mit dem Kloster verbundenen Adelsfamilien und die politischen Verhältnisse angesehen,

2 Vgl. Zeller, Die Umwandlung (wie Anm.1) S. $329 \mathrm{f}$.

3 Vgl. ebd., S. 323-330.

${ }^{4}$ Vgl. ebd., S. 347.

5 Vgl. ebd., S. 342.

6 Vgl. ebd., S.341 f.; zumindest vidimierte Albrecht am 4. Februar 1460 die Bulle in Ellwangen, vgl. ebd., S.16, S.21.

7 „Der Mitwirkung des Grafen Ulrich V. von Württemberg bei der Säkularisation des seinem Schirm anvertrauten Stifts wird auffallenderweise in den Quellen nirgends gedacht", ebd., S. 342; „[...] die auffallende Tatsache [..], daß der württembergische Graf in gar keinem Zusammenhang mit diesem so außerordentlichen Vorgang erwähnt wird“, Alois SEILER, Der württembergische Schutz und Schirm über Kloster und Stift Ellwangen (1370-1590), in: ZWLG 28 (1969) S.343-362, hier S.356; „Über die Rolle Graf Ulrichs, des Schirmers, bei diesen Vorgängen schweigen die Quellen“, Dieter Stievermann, Landesherrschaft und Klosterwesen im spätmittelalterlichen Württemberg, Sigmaringen 1989, S. 266.

${ }^{8}$ Es reicht von der Betonung seiner zentralen Stellung bei ZELLER („So dürfen wir trotz des völligen Schweigens der vorhandenen Quellen an der entscheidenden Mitwirkung des Schirmvogts nicht zweifeln“; Zeller, Die Umwandlung (wie Anm.1) S. 343) bis hin zu einer höchst verhaltenen Parteinahme bei Stievermann („Er hat sich diesem Projekt [...] wohl nicht entgegenstellen können“; Stievermann, Landesherrschaft (wie Anm.7) S. 266). 
die allerdings nur stichpunktartig benannt werden ${ }^{9}$. Dieter Stievermann hat dies in seiner Studie zu „Landesherrschaft und Klosterwesen im spätmittelalterlichen Württemberg“ pointiert zusammengefasst: „Überhaupt demonstrierte die Ellwanger Säkularisation unter einem den Bursfeldern geneigten Papst und mit einem reformfreudigen Schirmherrn, durchgeführt von einem ebenfalls zu Reformen tendierenden Bischof, mit hinreichender Deutlichkeit die sozialen und politischen Zwänge, die den konkreten Spielraum in der Klosterpolitik begrenzten. "10

Aber kann man, auch wenn Graf Ulrich V., Kardinal Peter und Papst Pius II. zweifelsohne der Kirchen- und Klosterreform gegenüber aufgeschlossen waren, ihre bevorzugte politische Schwerpunktsetzung darauf beschränken? Reagierten sie nur auf anderweitige Zwänge, wenn sie in einer bestimmten politischen Konstellation einmal keine Klosterreform betrieben? Oder wäre nicht auch denkbar, dass sie unterschiedlichen persönlichen und politischen Präferenzen folgten und diese situativ mehr oder weniger stark gewichteten? Folgt man dieser Überlegung, könnte die Unterstützung der Umwandlung Ellwangens nicht nur als bloßes defensives Zurückweichen in einer multiplen Zwangslage, sondern vielmehr als bewusst gewähltes politisches Mittel zum Erreichen bestimmter Ziele angesehen werden. Hierzu müssten die Ellwanger Ereignisse jedoch stärker, als dies bisher geschehen ist, in den politischen Kontext ihrer Zeit gestellt werden.

In diesem Zusammenhang ist vor allem die Rolle Markgraf Albrecht Achilles' von Brandenburg in den Blick zu nehmen, der bisher in der Forschung allenfalls als Befürworter der Umwandlung beim Papst und gegebenenfalls noch als Überbringer der Bulle nach Ellwangen erwähnt wird. Zeller wirft die Frage auf, lässt sie aber offen, „was Albrecht zu seinem Eingreifen in diese, ihn wenigstens nicht direkt berührende Angelegenheit bewogen hat. "11 Der Versuch einer Antwort erscheint angesichts von Albrechts Bedeutung in den zeitgenössischen regionalen und überregionalen Konfliktfeldern ebenso überfällig wie viel versprechend.

Diesen Fragen und Überlegungen soll in folgenden Schritten nachgegangen werden: Zunächst sollen Grundzüge der benediktinischen Klosterreform des 15. Jahrhunderts referiert werden, um darin die Besonderheiten der Ellwanger Situation,

9 „[...] ebensosehr freilich dürfte für ihn die Rücksicht auf seine Ritterschaft bestimmend gewesen sein, deren Unterstützung er gerade damals - am Vorabend des pfälzisch-bayerischen Krieges - nicht entbehren konnte“; ZELLER, Die Umwandlung (wie Anm. 1) S.343; „Württemberg nahm bei diesen Vorgängen unverkennbar Rücksicht auf den Ellwanger Stiftsadel“; Volker Press: Ellwangen, Fürststift im Reich des späten Mittelalters und der frühen Neuzeit, in: Ellwanger Jahrbuch 30 (1983/1984) S.7-30, hier S. 9 f.; „[...] die Ellwanger Wirklichkeit und die Spannungen mit den Wittelsbachern, die besondere Rücksichtnahmen auf den an Ellwangen interessierten Adel notwendig machten, dürften seine zumindest stillschweigende Zustimmung erkauft haben“; Stievermann, Landesherrschaft (wie Anm. 7) S. 266.

10 Stievermann, Landesherrschaft (wie Anm. 7) S. 266.

11 Zeller, Die Umwandlung (wie Anm. 1) S. 342. 
insbesondere der Jahre 1459/1460, verorten zu können. Sodann soll die Lage des Klosters Ellwangen in Beziehung zum Vorfeld und dem Beginn des Fürstenkriegs im Zeitraum 1458 bis 1460 gesetzt werden. Abschließend möchte ich meine Hypothesen zur Rolle und dem Zusammenwirken der an der Umwandlung beteiligten Akteure vorstellen und ihr Handeln im Ellwanger Fall in die politischen Handlungsmuster einordnen, die sich entweder direkt im Fürstenkrieg oder allgemein in ihrem politischen Wirken erkennen lassen.

\section{Grundzüge der benediktinischen Klosterreform und der Verfassung der Abtei Ellwangen im 15. Jahrhundert}

Mittelalterliche Reformansätze für die Benediktiner bewegen sich in der Regel auf zwei Ebenen: Einerseits geht es um bestimmte inhaltliche Forderungen zur Lebensführung der Mönche ${ }^{12}$, die in der Regel als Wiederherstellung der Regula Benedicti gerechtfertigt werden ${ }^{13}$, und andererseits geht es um die Form, in der diese überhaupt erst durchgesetzt werden sollen, das heißt organisatorische Innovationen ${ }^{14}$ : Jüngere Orden weisen in der Regel - wenn auch in unterschiedlichen Ausformungen - eine stärker ausgearbeitete Struktur über das einzelne Kloster hinaus auf, die eben eine stärkere Kontrolle der einzelnen Klöster durch den Verband zulässt. Bei den Benediktinerklöstern gab es dagegen eine Vielzahl von Organisationsformen: Eine große Zahl autonomer Klöster stand neben Klosterfamilien und anderen Verbandsformen.

12 Der „materiale Reformbegriff“ nach Dieter MerTEns, Monastische Reformbewegungen des 15. Jahrhunderts: Ideen - Ziele - Resultate, in: Reform von Kirche und Reich zur Zeit der Konzilien von Konstanz (1414-1418) und Basel (1431-1449). Konstanz-Prager Historisches Kolloquium (11.-17. Oktober 1993), hg. von Ivan HlavÁčeK/Alexander PaTscHOvsky, Konstanz 1996, S.157-181, hier S. 168-170.

13 Vgl. Petrus Becker, Erstrebte und erreichte Ziele benediktinischer Reformen im Spätmittelalter, in: Reformbemühungen und Observanzbestrebungen im spätmittelalterlichen Ordenswesen (Berliner Historische Studien, Bd.14; Ordensstudien, Bd.6), hg. von Kaspar ELM, Berlin 1989, S. 23-34, hier S. 26. Schon Becker relativiert diese Legitimationsstrategie, deutlich kritischer Immo EBERL, Stiftisches Leben in Klöstern. Zur Regeltreue im klösterlichen Alltag des Spätmittelalters und der frühen Neuzeit, in: Studien zum Kanonissenstift (Veröffentlichungen des Max-Planck-Instituts für Geschichte, Bd.167; Studien zur Germania Sacra, Bd.24), hg. von Irene Crusius, Göttingen 2001, S.275-315.

14 Vgl. zum gesamten Abschnitt Franz Josef Felten, Die Ordensreformen Benedikts XII. unter institutionengeschichtlichem Aspekt, in: Institutionen und Geschichte. Theoretische Aspekte und mittelalterliche Befunde (Norm und Struktur, Bd.1), hg. von Gert Melville, Köln u.a. 1992, S.369-435, hier S.369-374; Petrus Becker, Benediktinische Reformbewegungen im Spätmittelalter. Ansätze, Entwicklungen, Auswirkungen, in: Untersuchungen zu Kloster und Stift (Veröffentlichungen des Max-Planck-Instituts für Geschichte, Bd.68; Studien zur Germania Sacra, Bd.14), hg. vom Max-Planck-Institut für Geschichte, Göttingen 1980, S.167-187, hier S.168f. 
Als erster arbeitete Papst Benedikt XII. in der Bulle „Benedictina“ aus dem Jahre 1336 ein umfassendes Reformkonzept aus: Er definierte territoriale Einheiten, sogenannte Provinzen, in denen regelmäßig tagende Provinzialkapitel die Äbte der jeweiligen Klöster versammeln und Visitationen der einzelnen Klöster durchführen sollten ${ }^{15}$. Im Heiligen Römischen Reich nördlich der Alpen gab es vier dieser Provinzen, die größte davon war die Kapitelsprovinz ${ }^{16}$ Mainz-Bamberg, die die Mainzer Kirchenprovinz und das exemte Bistum Bamberg umfasste ${ }^{17}$. Dieses Konzept blieb im Heiligen Römischen Reich zunächst Theorie, sollte aber langfristig wirksam werden ${ }^{18}$.

Dies geschah auf und nach dem Konzil von Konstanz ${ }^{19}$, das sich die causa reformationis explizit zum Ziel gesetzt hatte: Im Auftrag des Konzils tagten vom

15 Vgl. Felten (wie Anm.14), S. 399.

16 Dieter Mertens schlägt den Begriff „Kapitelsprovinzen“ vor, „da es sich [bei ihnen] nicht um die einen verfaßten Orden untergliedernden Ordensprovinzen handelt, sondern um die in Anlehnung an die Metropolitanverfassung der Amtskirche zum Zweck der Konstituierung von Kapiteln vorgenommene Zusammenfassung benediktinischer Klöster“; Dieter Mertens, Reformkonzilien und Ordensreform im 15. Jahrhundert, in: Reformbemühungen und Observanzbestrebungen (wie Anm.13) S. 445.

17 Vgl. Joseph Zeller, Das Provinzialkapitel im Stifte Petershausen im Jahre 1417. Ein Beitrag zur Geschichte der Reformen im Benediktinerorden zur Zeit des Konstanzer Konzils, in: Studien und Mitteilungen zur Geschichte des Benediktinerordens Neue Folge 10 (1922) S. 1-73, hier S. 8.

18 Vgl. BecKer, Benediktinische Reformbewegungen (wie Anm. 14) S. 169; neuerdings zu den Fernwirkungen auf die neuzeitlichen benediktinischen Verfassungsformen Stephan HAERING, Spätmittelalterliche monastische Reforminitiativen in der benediktinischen Welt. Die Reformen von Santa Giustina in Padua und von Subiaco sowie das Provinzialkapitel zu Petershausen in kirchenrechtlicher Perspektive, in: Die benediktinische Klosterreform im 15. Jahrhundert (Veröffentlichungen des Grabmann-Institutes zur Erforschung der mittelalterlichen Theologie und Philosophie, Bd.56), hg. von Franz Xaver Bischof/Marin ThurNER, Berlin 2013, S. 55-73, hier S. 69-73.

19 Zur neueren Literatur vgl. die Sammelrezension von Ansgar Frenken, Rezension zu: Jan Keupp/Jörg Schwarz, Konstanz 1414-1418. Eine Stadt und ihr Konzil, Darmstadt 2013; Sandra WolfF, Die „Konstanzer Chronik“ Gebhart Dachers. „By des Byschoffs zyten volgiengen disz nachgeschriben ding vnd sachen ...“. Codex Sangallensis 646: Edition und Kommentar, Ostfildern 2008; Ulrich Richental. Chronik des Konzils zu Konstanz: 1414-1418, hg. von Jürgen Klöckler, Stuttgart 2013; Thomas Buck/Herbert Kraume, Das Konstanzer Konzil. Kirchenpolitik - Weltgeschehen - Alltagsleben, Ostfildern 2013; Das Konstanzer Konzil 1414-1418. Weltereignis des Mittelalters. Essays, hg. von KarlHeinz Braun u.a., Stuttgart 2013; Rom am Bodensee. Die Zeit des Konstanzer Konzils, hg. von Silvia Volkart, Zürich 2014; Augenzeuge des Konstanzer Konzils. Die Chronik des Ulrich Richental, hg. von Henry Gerlach/Monika KüBle (Übers.), Darmstadt 2014; Das Konstanzer Konzil als europäisches Ereignis. Begegnungen, Medien und Rituale, hg. von Gabriela Signori/Birgit Studt, Ostfildern 2014; Heribert Müller, Die kirchliche Krise des Spätmittelalters. Schisma, Konziliarismus und Konzilien, München 2012; Das Konstanzer Konzil 1414-1418. Weltereignis des Mittelalters. Katalog zur großen Landesausstellung Baden- Württemberg in Konstanz vom 27. April bis zum 21. September 2014, 
28. Februar bis zum 19. März 1417 im Kloster Petershausen vor den Toren der Stadt Vertreter von fast 130 Klöstern zum ersten Provinzialkapitel der Kapitelsprovinz Mainz-Bamberg ${ }^{20}$. Das Kapitel definierte nicht nur Vorschriften zur Lebensweise in den Klöstern, die durch regelmäßig durchzuführende Visitationen der Klöster mittels eines umfangreichen und stark ins Detail gehenden Fragenkatalogs umgesetzt werden sollten ${ }^{21}$, sondern traf auch Regelungen für seine Verstetigung: Seine Präsidenten fungierten bis zum nächsten Kapitel als gewählte Geschäftsträger $^{22}$, das nächste Kapitel wurde bereits terminiert, weiterhin wurden Regelungen für eine Kasse getroffen und Visitatoren bestellt ${ }^{23}$. Fortan tagten die Versammlungen regelmäßig alle zwei bis drei Jahre ${ }^{24}$. So wurde es zu einem nicht zu vernachlässigenden Akteur der Reform ${ }^{25}$, der sich im Laufe des 15. Jahrhunderts zunehmend radikalisierte. Dies zeigt sich an einem neuralgischen Punkt: Der adligen Exklusivität vieler alter Konvente, die der Versorgung nachgeborener Familienmitglieder diente und im Kloster mit adelsgemäßen Lebensformen, Privateigentum, Pfründen und Präsenzgeldern für die Mönche nach dem Vorbild von Stiftskapiteln einherging ${ }^{26}$. Klaus Schreiner hat auf die unterschiedlichen Verwendungsweisen des Begriffs „Adelsspital“ hingewiesen: Für die Adligen war es ein Legitimations-, für die Reformer, häufig Bürgerliche, ein Kampfbegriff ${ }^{27}$. In Petershausen wurde

hg. vom Badischen Landesmuseum, Darmstadt 2014; Thomas A. Fudge, The Trial of Jan Hus. Medieval Heresy and Criminal Procedure, Oxford 2013; in: H-Soz-Kult, 11.02.2015 (www.hsozkult.de/publicationreview/id/rezbuecher-23399, abgerufen am 17.01.2017).

20 Zeller, Das Provinzialkapitel (wie Anm.17) S.26f. Sein Aufsatz ist nach wie vor grundlegend. Eine neuere Zusammenfassung zum Petershausener Kapitel bei HaERING (wie Anm.18) S.63-68.

${ }^{21}$ Zeller, Das Provinzialkapitel (wie Anm. 17) S. 28.

22 Vgl. ebd., S. 18.

23 Vgl. ebd., S. 29.

${ }^{24}$ Vgl. Joseph Zeller, Liste der Benediktiner-Ordenskapitel in der Provinz MainzBamberg seit dem Konstanzer Konzil, in: Studien und Mitteilungen zur Geschichte des Benediktinerordens und seiner Zweige Neue Folge 11 (1924) S. 184-193.

25 Die Einschätzung Beckers scheint mir - auch gegenüber der pessimistischeren, neueren Auffassung Haerings (vgl. DeRs. [wie Anm. 18] S. 68) - nach wie vor zutreffend: „Die Bedeutung der Provinzialkapitel und der Benedictina scheint mir in der Geschichtsschreibung zu gering bewertet, weil kein unmittelbarer Erfolg sichtbar sei [...]. [Jedoch:] Die Zusammenkünfte der Äbte und die Möglichkeit, gleichgesinnte Reformleute zu finden, sich mit diesen auszusprechen und abzusprechen, sind nicht zu unterschätzen“; BECKER, Benediktinische Reformbewegungen (wie Anm.14) S.169.

${ }^{26}$ Vgl. zu Ellwangen Zeller, Die Umwandlung (wie Anm.1) S.296-305, eine kurze Zusammenfassung bei Pfeifer (wie Anm. 1) S. 55-57.

27 Vgl. Klaus Schreiner, Vom adligen Hauskloster zum „Spital des Adels“. Gesellschaftliche Verflechtungen oberschwäbischer Benediktinerkonvente im Mittelalter und in der frühen Neuzeit, in: Rottenburger Jahrbuch für Kirchengeschichte 9 (1990) S. 27-54, hier S. 41. 
das Adelsprivileg erstmals abgemildert ${ }^{28}, 1456$ auf dem Provinzialkapitel in Erfurt das Adelsprivileg gänzlich aufgehoben ${ }^{29}$.

Dabei waren die Provinzialkapitel nur eine Reformkraft unter vielen, die teils parallel wirkten, teils sich gegenseitig verstärkten ${ }^{30}$ : Seit jeher galt das Visitationsrecht der Bischöfe. Daneben traten immer stärker, ebenfalls seit dem Konstanzer Konzil, auf dem die ersten Privilegien dieser Art vergeben wurden, weltliche Landesfürsten auch als Klosterreformer auf, aus einer Mischung von geistlichen und weltlichen Motiven ${ }^{31}$. Dieter Stievermann hat dies für Württemberg beispielhaft untersucht ${ }^{32}$. Im Orden selbst entwickelten sich Reformkongregationen, zunächst unter dem Einfluss von Subiaco die Reformen von Kastl ${ }^{33}$ und Melk ${ }^{34}$, diese vor allem in Süddeutschland, ab den Dreißiger Jahren des 15. Jahrhunderts die immer bedeutsamer werdende Bursfelder Kongregation, die zunehmend auch nach Süddeutschland ausgriff ${ }^{35}$.

Die adligen Konvente leisteten dagegen in vielen Fällen hartnäckigen Widerstand, Reformen waren langwierig und bedurften häufig mehrerer Anläufe ${ }^{36}$. Letztlich waren sie oft erfolgreich ${ }^{37}$. Nur wenigen Ausnahmefällen, meist sehr privilegierten reichsunmittelbaren Abteien wie Fulda und Kempten gelang es, als Benediktinerklöster ihre adlige Lebensform weiterzuführen ${ }^{38}$.

Eine spezielle Form der Reaktion auf die Ordensreform stellt der Rechtsformwechsel in ein Säkularkanonikerstift dar. Eine Umwandlung dieser Art war kirchenrechtlich nicht unproblematisch. Für Einzelpersonen galt der Grundsatz, dass ein Wechsel der geistlichen Lebensform nur in Richtung der vita arctior, der stren-

28 Vgl. Zeller, Das Provinzialkapitel (wie Anm. 17) S.36; Klaus Schreiner, Mönchsein in der Adelsgesellschaft des hohen und späten Mittelalters. Klösterliche Gemeinschaftsbildung zwischen spiritueller Selbstbehauptung und sozialer Anpassung, in: HZ 248 (1989) S. 557-620, hier S. $598 \mathrm{f}$.

${ }^{29}$ Vgl. Wendehorst (wie Anm.1) S.337.

30 Vgl. Birgit Studt, Papst Martin V. und die Kirchenreform in Deutschland (Forschungen zur Kaiser- und Papstgeschichte des Mittelalters. Beihefte zu J.F.Böhmer, Regesta Imperii, Bd.23), Köln/Weimar/Wien 2004, S. 76.

31 Ebd., S.79-81.

32 Vgl. Stievermann, Landesherrschaft (wie Anm.7).

33 Vgl. Becker, Benediktinische Reformbewegungen (wie Anm. 14) S. 173.

${ }^{34}$ Vgl. ebd., S. $174 \mathrm{f}$.

35 Vgl. ebd., S. 181-183.

36 Einige Beispiele nennt Schreiner, Mönchsein (wie Anm.28) S.605f. (Michelsberg bei Bamberg); S.608-610 zu Frauenklöstern; sowie Ders., Vom adligen Hauskloster (wie Anm. 27) S.42f. (Alpirsbach, Urspring); weitere Beispiele bei Wendehorst (wie Anm.1) S.334f. (Amorbach); S. 336 (Münsterschwarzach); 339f. (Michelsberg bei Bamberg); S. 344 (Murrhardt).

37 Zum Beispiel erreichte die Reformbewegung von Kastl bis 1450 ca. 25 Klöster, vgl. Becker, Benediktinische Reformbewegungen (wie Anm. 14) S. 175, die Bursfelder Kongregation bis zum Ende des 15. Jahrhunderts 95 Konvente, vgl. ebd., S. 182.

38 Vgl. Schreiner, Mönchsein (wie Anm.36) S.615-619. Eine ausführliche Darstellung zu Kempten bei Ders., Vom adligen Hauskloster (wie Anm. 27) S. 44-54. 
geren Lebensweise, erlaubt sei ${ }^{39}$. Davon ist der Umgang mit einer geistlichen Einrichtung zu unterscheiden ${ }^{40}$ : Grundsätzlich konnte eine solche von einer Rechtsform zu einer anderen umgewandelt werden, genauer gesagt, die alte Einrichtung wurde aufgehoben, die neue errichtet, und zwar aus der Vermögensmasse der alten, und die Personen wechselten gleichfalls ${ }^{41}$. Dies war jedoch nur aus besonderen Gründen (iusta causa) möglich, zum Beispiel wenn eine Einrichtung ihren Zweck nicht mehr erfüllte, oder zur Verbesserung des Gottesdienstes ${ }^{42}$.

Im Denken der Zeit scheint der Weg vom Kloster zum Stift nahegelegen zu haben $^{43}$, denn immer wieder wird die verfassungsmäßige Nähe der stiftsmäßig lebenden Klöster, die nur noch dem Namen nach Klöster seien, zu den Säkularinstituten betont ${ }^{44}$. De facto war eine solche Genehmigung aber schwierig zu erlangen - sonst hätten viel mehr Klöster davon Gebrauch gemacht. Es galt nicht nur, die kirchlich und weltlich für den jeweiligen Konvent Zuständigen auf seine Seite zu bringen, sondern es bedurfte auch geeigneter Verbindungspersonen an der Kurie und des Einsatzes immenser finanzieller Mittel ${ }^{45}$.

Nur einer kleinen Gruppe von Konventen gelang es daher, sich in adlige Säkularkanonikerstifte oder Ritterstifte, wie der zeitgenössische Terminus lautet, umwandeln zu lassen. St. Alban vor Mainz war 1419 der erste Fall, in direkter Konsequenz auf den Beschluss des Provinzialkapitels zu Petershausen, das nächste Kapitel in St. Alban abzuhalten ${ }^{46}$. Zehn weitere Abteien der Kapitelsprovinz sollten bis in das beginnende 16. Jahrhundert hinein folgen ${ }^{47}$. Sie wurden jeweils heftig vom

39 Vgl. Moraw (wie Anm.1) S. 19.

40 Vgl. Zeller, Die Umwandlung (wie Anm.1) S. 330.

${ }^{41}$ Vgl. Paul Hinschius, Das Kirchenrecht der Katholiken und Protestanten. System des katholischen Kirchenrechts mit besonderer Berücksichtigung auf Deutschland, Bd. 2, Berlin 1883 (ND Graz 1959), S. 396, S. 454-459.

42 Vgl. ebd., S.386, S.396.

43 Diese Formulierung ist inspiriert von Moraws Diktum: „Der Weg ins Stift war kürzer als in die Reformkongretation“; Moraw (wie Anm. 1) S. 19.

44 Vgl. ebd., Das Argument begegnet zeitgenössisch zur Begründung der Umwandlungen von St. Alban, vgl. Schmid (wie Anm.1) S.258, St. Leodegar, vgl. Heinzer (wie Anm.1) S. 15 und Ellwangen, vgl. Zeller, Die Umwandlung (wie Anm. 1) S. 337 f.

45 Zum letzten Punkt: Vgl. Zeller, Die Umwandlung (wie Anm. 1) S. 337 zur Vollmacht für den Prokurator, für die Bestreitung der Kosten für die Umwandlung bis zu 1.000 Gulden Kredit aufzunehmen; vgl. weiterhin Scнмid (wie Anm. 1) S. 247-249 zu Kreditaufnahmen von St. Alban im Vorfeld der Umwandlung sowie zur Aussetzung einer Leibrente für den Prokurator St. Albans an der Kurie, die explizit mit dessen hohen Auslagen begründet wird.

${ }^{46}$ Vgl. ebd., S. 245-247.

47 Die Zahl bezieht sich auf alle Fälle adliger Konvente in der Ordensprovinz Mainz-Bamberg, vgl. die Übersicht bei Zeller, Die Umwandlung (wie Anm. 1) S. 335. Er summiert mit St. Alban und St. Vitus (Ellwangen) auf insgesamt 10 Klöster, führt aber namentlich 11 Konvente auf. In Zeller, Das Provinzialkapitel (wie Anm.17) S. 44 wiederholt er die falsche Summe und nennt zusätzlich noch St. Leodegar in Luzern. - Bei Moraw (wie Anm. 1) S. 19 findet sich nur eine unvollständige Aufzählung, die St. Leodegar in Luzern beinhaltet (das 
Provinzialkapitel verfolgt, das - wenn auch ohne Erfolg - nichts unversucht ließ, um die Umwandlungen rückgängig zu machen: Von Prozessen an der Kurie ${ }^{48}$ über den Aufruf, den Stiften die bisherigen Abgaben und die Gefolgschaft zu verweigern $^{49}$, bis hin zu wütenden Anklagen und Verleumdungen ${ }^{50}$.

Die Umwandlung der Abtei Ellwangen sollte etwa dreißig Jahre später folgen. Die Situation des Klosters zur Mitte des 15. Jahrhunderts lässt sich wie folgt skizzieren: Ellwangen war Fürstpropstei, sein Abt war Reichsfürst; das Kloster verfügte seit Ende des 14. Jahrhunderts wieder über die Klostervogtei ${ }^{51}$. Als sein vom König eingesetzter Schirmer fungierten die Grafen von Württemberg ${ }^{52}$. Auch wenn Ellwangen so gut wie möglich darauf achtete, seine Eigenständigkeit zu wahren, so war der württembergische Einfluss auf den Konvent doch beträchtlich. So setzten die Schirmer den einzigen bürgerlichen Abt durch, den das Kloster je hatte: Siegfried Gerlacher, der zwar einer der Präsidenten des Petershausener Reformkapitels war, im Kloster jedoch keine Reform erreichen konnte ${ }^{53}$.

Das Kloster betrachtete sich als exemt; dennoch versuchte der Augsburger Bischof vielfach, Einfluss auf den Konvent zu nehmen ${ }^{54}$. Dem Kloster war es zwar gelungen, einen recht geschlossenen Herrschaftsbereich aufzubauen ${ }^{55}$, aber seine ökonomische Situation war seit ca. 1250 durchgehend schlecht und von hohen Schulden, die es nicht dauerhaft abtragen konnte, geprägt ${ }^{56}$. Die regelmäßig wiederkehrenden Sparmaßnahmen wurden häufig kombiniert mit Reformversuchen zur Lebensführung der Mönche ${ }^{57}$.

allerdings nicht exklusiv adlig war, vgl. Anm.1); weiterhin nennt er Wülzburg bei Weißenburg in Bayern, das jedoch zum Bistum Eichstätt und damit nicht zur Ordensprovinz Mainz-Bamberg gehörte.

${ }^{48}$ Vgl. zu Ellwangen Zeller, Die Umwandlung (wie Anm. 1) S.353-361; zu St. Alban Wolfgang Dobras, Mainz, St. Alban, in: Die Männer- und Frauenklöster der Benediktiner in Rheinland-Pfalz und im Saarland (Germania Benedictina, Bd.9), in Verbindung mit Regina E. Schwerdtfeger, bearb. von Friedhelm Jürgensmeier, St. Ottilien 1999, S. 445 - 469, hier S. 454.

49 Vgl. Wendehorst (wie Anm. 1) S. 346.

50 Ein Beispiel bietet die benediktinische Prozessschrift gegen St. Alban, vgl. Schmid (wie Anm. 1) S. 269-272; als geradezu klassisch können die Invektiven Johannes Trithemius' gegen die Umwandlungen gelten, vor allem in seinem 1493 entstandenen Werk „Liber lugubris de statu et ruina monastici ordinis“, vgl. Zeller, Die Umwandlung (wie Anm.1) S. 331 -333, dort auch mit genauen Angaben zu den verschiedenen Druckfassungen.

51 Vgl. Dieter Stievermann, Das geistliche Fürstentum Ellwangen im 15. und 16. Jahrhundert. Politische Selbstbehauptung im Schatten Württembergs, in: Ellwanger Jahrbuch 32 (1987/88) S. 35-47, hier S. 35 f.

52 Vgl. ebd., S. 36 .

53 Vgl. ebd., S. 39 f.

54 Vgl. ebd., S. 40.

55 Vgl. Press (wie Anm. 9) S. 8.

56 Vgl. Pheifer (wie Anm.1) S. 55.

57 Vgl. Stievermann, Das geistliche Fürstentum (wie Anm. 51) S.39-42. 
Zur inneren Verfassung des Klosters: Wie in vielen Klöstern waren Abts- und Konventsgut getrennt worden ${ }^{58}$, und der Konvent konnte über sein Gut eigenständig entscheiden ${ }^{59}$. Dem Abt stand das Kapitel gegenüber, in der Regel (wenn die Position nicht gerade einer Sparung unterlag ${ }^{60}$ ) vertreten durch den Dekan ${ }^{61}$. Die adligen Konventualen bezogen Pfründen aus den Einkünften des Klosters; mit speziellen Ämtern waren weitere Pfründen verbunden ${ }^{62}$. Spätestens seit Beginn der 1440er Jahre war, als Folge der Pest und zweier Brände, die Vita communis aufgehoben; die Mönche residierten in eigenen Häusern in der Stadt Ellwangen ${ }^{63}$. Dem Abt stand unter anderem das Abtsschloss über der Stadt zur Verfügung ${ }^{64}$. Zwar war die Zahl der Konventualen auf 20 eingeschränkt worden, aber der Konvent erreichte nur etwa die Hälfte an Mitgliedern ${ }^{65}$. Die Profess wurde häufig nicht abgelegt $^{66}$. Der Konvent rekrutierte sich aus nachgeborenen Söhnen der umliegenden Adelsfamilien, die ein hohes Interesse am Konvent zeigten ${ }^{67}$ und deren Netzwerke auch an die Höfe der benachbarten Hochadligen ${ }^{68}$ und Bischöfe und in die Domkapitel reichten ${ }^{69}$. Das adlige Selbstverständnis der Mönche zeigt sich auch im Einzelfall in Anklagen wegen Raufereien, Gewalttätigkeiten und ausschweifender Lebensführung ${ }^{70}$.

\section{Ellwangen in den 1450er Jahren: Vorgeschichte und Ablauf der Umwandlung}

Die Geschichte Ellwangens in den 1450er Jahren ist von drei Faktoren geprägt: Einflussnahmen des weltlichen Schirmers und des Bischofs aus deutlichem Eigeninteresse, mehrere Interventionen in Form von Sparmaßnahmen und Reformversuchen sowie interne Spannungen im Konvent. 1450 erhielt Bischof Peter von

58 Vgl. Zeller, Die Umwandlung (wie Anm. 1) S. 300.

${ }^{59}$ Vgl. ebd., S. 395.

60 Dies war beispielsweise von 1445-1554 der Fall gewesen, vgl. ebd., S. 326.

61 Vgl. ebd., S. $397 \mathrm{f}$.

62 Vgl. ebd., S. $300 \mathrm{f}$.

63 Vgl. ebd., S. 299.

64 Vgl. ebd., S. 5.

65 Vgl. ebd., S. 297.

66 Vgl. ebd., S. 419.

${ }^{67}$ Dies zeigt sich zum Beispiel in der Einflussnahme von Familienangehörigen der Mönche anlässlich der strittigen Abtsnachfolge 1452/1453, vgl. Stievermann, Das geistliche Fürstentum (wie Anm. 51) S.41, sowie der Sparung 1454, vgl. Zeller, Die Umwandlung (wie Anm.1) S. 328.

68 Beispielsweise standen die meisten adligen Familien im Umfeld Ellwangens auch im Dienste Württembergs oder hatten Lehen der Württemberger inne, vgl. Stievermann, Das geistliche Fürstentum (wie Anm. 51) S.35, S. 42.

69 Für Augsburg soll dies im letzten Teil des Aufsatzes dargestellt werden.

70 Diese wurden dem späteren Abt Johann von Holzingen zur Last gelegt, vgl. ZeLLer, Die Umwandlung (wie Anm.1) S. 308. 
Schaumberg die Kardinalswürde und ließ sich vom Papst zum Amtsantritt die nächsten beiden freiwerdenden Abteien als Kommenden versprechen. Ellwangen, das davon betroffen gewesen wäre, gelang es, den Status als Kommende durch Zahlung einer Leibrente an den Kardinal abzuwenden ${ }^{71}$.

1452/53 kam es nach dem Tod des alten Abts zu einem Schisma ${ }^{72}$ : Der Konvent wählte aus seiner Mitte Albrecht Schenk von Schenkenstein, die päpstliche Bestätigung erhielt jedoch der bisherige Scholaster des Augsburger Domkapitels Johann von Hürnheim. Er wurde neuer Abt (und verzichtete dann auf die Scholasterie und den Sitz im Domkapitel), nachdem aufgrund des Protests zahlreicher Adliger bei Kardinal Peter württembergische Räte im Mai 1453 einen Vergleich ausgehandelt hatten: Albrecht Schenk von Schenkenstein verzichtete gegen eine Leibrente aus der Abtsmensa auf seine Würde. Dies lässt den Einfluss des Kardinals, aber auch den des Grafen von Württemberg erkennen, in dessen Diensten Angehörige der von Hürnheim schon länger nachweisbar sind. Zugleich könnte hier auch schon ein Bezug zu Markgraf Albrecht Achilles von Brandenburg gegeben gewesen sein, da ein Walter von Hürnheim in den Jahren 1446-1448 als Hofmeister des Markgrafen nachgewiesen werden $\mathrm{kann}^{73}$.

Im Herbst 1453 wurde die nächste Sparung vorbereitet; ob sie tatsächlich zustande kam, ist unklar ${ }^{74}$. In den ersten Monaten des Jahres 1454 kam es gleich zweimal zu Sparungen und Reformversuchen ${ }^{75}$ : Zunächst durch Kardinal Peter mit Berufung auf Graf Ulrich V., dann wenige Monate später durch württembergische Räte. Diese änderten die ökonomischen Bestimmungen der ersten Sparung ab, die (vergleichsweise milden) Reformvorschriften für die Lebensweise blieben bestehen. Die Revision der Maßnahmen war vermutlich durch Konflikte zwischen Abt und Konvent, in die auch die Familien beider Parteien involviert waren, veranlasst.

1457 kam es wieder zu Auseinandersetzungen im Konvent ${ }^{76}$ : Der 1454 nach mehrjähriger Vakanz des Amtes eingesetzte Dekan, Ulrich von Holzingen, sah sich einer Opposition des Kapitels unter Führung von Georg vom Stein zu Diemantstein gegenüber, die an dessen Sparplänen Anstoß nahm. Kardinal Peter vermittelte: Ulrich von Holzingen verließ für drei Jahre den Konvent gegen eine Rente, Georg vom Stein wurde neuer Dekan. Er sollte in der späteren Umwandlung eine

71 Vgl. ebd., S. 320 .

72 Zum gesamten Vorgang vgl. ebd., S.320-322; Stievermann, Das geistliche Fürstentum (wie Anm. 51) S. 41.

73 Vgl. Hillay ZMora, Das Verhältnis Markgraf Albrecht Achilles' zum fränkischen Adel, in: Kurfürst Albrecht Achilles (1414-1486). Kurfürst von Brandenburg, Burggraf von Nürnberg (Jahrbuch des Historischen Vereins für Mittelfranken, Bd.102), hg. von Mario MülleR, Ansbach 2014, S. 235-248, hier S. 246.

74 Vgl. Zeller, Die Umwandlung (wie Anm. 1) S. 323-325; Stievermann, Das geistliche Fürstentum (wie Anm. 51) S. 41.

${ }^{75} \mathrm{Zu}$ beiden Vorgängen vgl. Zeller, Die Umwandlung (wie Anm.1) S.323-328; Stievermann, Das geistliche Fürstentum (wie Anm. 51) S. 41.

76 Vgl. Zeller, Die Umwandlung (wie Anm. 1) S. 328 f. 
führende Rolle als Vertreter des Konvents einnehmen. Hierfür war er vermutlich vor allem durch enge persönlichen Beziehungen zwischen Kardinal Peter und der Familie vom Stein zu Diemantstein qualifiziert: Franz vom Stein war Hofmeister Peters und Ehemann von dessen Schwester Margarethe gewesen ${ }^{77}$; einer seiner Neffen, Heinrich vom Stein, war Rat des Bischofs und Vogt zu Dillingen, der bischöflichen Residenzstadt ${ }^{78}$. Georg vom Stein war ein jüngerer Bruder Heinrichs ${ }^{79}$ und damit gleichfalls Neffe des Kardinals.

Im Umfeld des Klosters ist in dieser Zeit eher eine Stärkung der Reform zu beobachten: Wie schon erwähnt, beschloss im April 1456 das Provinzialkapitel in Erfurt die vollständige Aufhebung des Adelsprivilegs ${ }^{80}$. Im November 1456 ließ sich Kardinal Peter von Schaumberg ein Privileg zur Reform aller Klöster in seinem Amtsbereich, auch der exemten, verlängern ${ }^{81}$. Im März 1459 ließ sich auch Graf Ulrich V. ein Generalprivileg zur Reform aller Klöster in seinem Machtbereich ausstellen ${ }^{82}$. Im April 1459 tagte das Provinzialkapitel in Nürnberg, also nicht weit entfernt ${ }^{83}$. Im Oktober 1459 ging es in Ellwangen, wie eingangs erwähnt, um die Verlängerung der bestehenden Sparung; zugleich sollte der Konvent innerhalb von zwei Jahren Reformstatuten aufstellen und diese von einer Kommission aus württembergischen Vertrauten überprüfen lassen, der unter anderem Propst Wilhelm von Mönchsroth und Hans von Ahelfingen angehörten ${ }^{84}$.

Dann erfolgte die schon angesprochene grundlegende Wendung der Angelegenheit: Sie lässt sich erstmals am 26. Dezember 1459 feststellen, und zwar mit der

77 Vgl. Friedrich Zoepfl, Das Bistum Augsburg und seine Bischöfe im Mittelalter, München 1955, S.381; Helmut Lausser, Die Herren von Diemantstein. Ihre Tätigkeiten, Güter und verwandtschaftlichen Beziehungen im Umfeld des Landkreises Dillingen im Mittelalter, in: Jahrbuch des Historischen Vereins Dillingen an der Donau 95 (1993) S.34-151, hier S. 125.

78 Vgl. Lausser (wie Anm.77) S. 142 f.

79 Vgl. ebd., S. 150 f. - Allerdings irrt Lausser, wenn er Georg vom Stein zu Diemantstein die Stellung eines päpstlichen Protonotars und Domkapitulars des Augsburger Domkapitels zuschreibt (vgl. ebd.); der Irrtum in Bezug auf das Kanonikat findet sich auch bei ZELLer, Die Umwandlung (wie Anm.1) S. 322 sowie bei Albert Haemmerle, Die Canoniker des Hohen Domstiftes zu Augsburg bis zur Saecularisation, Zürich 1935, S.161, Nr. 803 a. Tatsächlich sind zwei Personen zu unterscheiden: Einerseits Georg vom Stein zu Diemantstein, der Dekan von Ellwangen, und anderseits Georg von Stein, der Rat Albrechts von Österreichs, päpstliche Protonotar und Kanoniker in Augsburg, vgl. zu diesem Rudolf Kneschke, Georg von Stein, Versuch einer Biographie, Weida i. Th. 1913 sowie die ihm zuzuordnenden Personenindizes im Repertorium Germanicum Online, RG VI 01445, RG VII 00682 und RG VIII 01406 (http://rg-online.dhi-roma.it/RG, abgerufen am 08. 06.2016).

80 Vgl. Anm. 29.

81 Vgl. Zoepfl (wie Anm. 77) S. 411.

82 Vgl. Stievermann, Landesherrschaft (wie Anm. 7) S. 265.

83 Vgl. Zeller, Liste (wie Anm. 24) S. 188.

${ }^{84}$ Vgl. Zeller, Die Umwandlung (wie Anm.1) S.329f. 
Bestellung des Dekans Georg vom Stein zum Prokurator an der Kurie durch den Abt und Konvent des Klosters mit dem Auftrag, die Genehmigung zur Umwandlung zu erreichen und der Vollmacht, bis zu 1.000 Gulden Kredit dafür aufzunehmen $^{85}$. In inhaltlichem Zusammenhang damit steht ein von Zeller ediertes Konzept für die Argumentation, die wohl der Supplik zugrunde liegen sollte ${ }^{86}$. Es ist in zwei Fassungen überliefert ${ }^{87}$ : Nur in der ersten, stark korrigierten Fassung heißt es, wenn die Umwandlung nicht gelänge, sollte zumindest eine Bestätigung der Privilegien des Klosters erworben werden. In der Endfassung fehlt dieser Passus ${ }^{88}$. Man kann meines Erachtens den herauskorrigierten Passus dennoch so interpretieren, dass der Konvent zumindest anfangs unsicher war, ob sein Vorstoß Erfolg haben würde.

Um die Jahreswende 1459/1460 reiste Markgraf Albrecht Achilles von Brandenburg nach Mantua ${ }^{89}$, wo Papst Pius II. gerade den sogenannten Fürstenkongress abhielt, mit dem Ziel, Unterstützung zu einem Kreuzzug gegen die Türken zu sammeln ${ }^{90}$. Dazu gewährte er im zeitlichen Umfeld den Grafen und Fürsten, die sich an ihn wandten, eine Reihe von Privilegien ${ }^{91}$, er forderte jedoch auch intensiv den Besuch seines Kongresses ein: Allein gegenüber Markgraf Albrecht sind im Verlauf des Jahres 1459 sechs Breven im Repertorium Germanicum verzeichnet, die sein Kommen anmahnen ${ }^{92}$. Dem folgte dieser nun in letzter Minute, kurz vor Ende des Tags Mitte Januar $1460^{93}$, und setzte sich dort erfolgreich für die Umwandlung ein ${ }^{94}$. Am 14. Januar 1460 wurde die Bulle für die Umwandlung von Ellwangen ausgestellt ${ }^{95}$, in zeitlichen Zusammenhang zu anderen, ihn direkt angehenden Privilegien ${ }^{96}$. Am 4. Februar 1460 vidimierte Markgraf Albrecht sie in

85 Vgl. ebd., S. $336 \mathrm{f}$.

86 Vgl. ebd., S. 7-11.

87 Vgl. ebd., S. 7.

88 Vgl. ebd., S. 11.

89 Vgl. ebd., S. $342 \mathrm{f}$.

90 Vgl. ebd., S. $338 \mathrm{f}$.

91 Vgl. Dieter Stievermann, Die württembergischen Klosterreformen des 15. Jahrhunderts. Ein bedeutendes landekirchliches Strukturelement des Spätmittelalters und ein Kontinuitätsstrang zum ausgebildeten Landeskirchentum der Frühneuzeit, in: ZWLG 44 (1985) S. 65-103, hier S. $77 \mathrm{f}$.

92 Vgl. Repertorium Germanicum Online, RG VIII 00076 (http://rg-online.de.dhi-roma. it/RG/8/76, abgerufen am 10.06.2016).

$93 \mathrm{Vgl}$. Zeller, Die Umwandlung (wie Anm.1) S.338f., der darauf hinweist, dass die Umwandlungsbulle für Ellwangen am Abschlusstag des Kongresses, dem 14. Januar 1460, ausgestellt wurde.

94 Vgl. Zeller, Die Umwandlung (wie Anm.1) S. $341 \mathrm{f}$.

95 Vgl. ebd., 338 f.; Repertorium Germanicum Online, RG VIII 02780 (http://rg-online. de.dhi-roma.it/RG/8/2780, abgerufen am 22.05.2016).

96 Es handelte sich um ein umfangreiches Privileg an ihn und seine Brüder betreffend eine Reihe von geistlichen Einrichtungen der Brandenburger vom 11. Januar 1460, vgl. Repertorium Germanicum Online, RG VIII 01212 (http://rg-online.de.dhi-roma.it/RG/8/1212, abgerufen am 10.06.2016); weiterhin die Erlaubnis zum Mitführen eines Tragaltars vom 
Ellwangen, woraus geschlossen werden kann, dass er sie vermutlich selbst dorthin gebracht hatte ${ }^{97}$.

Zum Vollzug der Umwandlung wurde Kardinal Peter von Schaumberg bestellt ${ }^{98}$. Es schlossen sich im März 1460 Verhandlungen in Dillingen zwischen dem Dekan des Klosters, Georg zum Stein, als Vertreter des Konvents und Kardinal Peter an, in denen der Kardinal erkennen ließ, dass er ein funktionstüchtiges Stift schaffen wollte, und seine Vorstellungen gegenüber Abt und Konvent, die ihn zeitweise $\mathrm{zu}$ hintergehen versuchten, mit hoher Autorität durchsetzte ${ }^{99}$. Dabei traten mit Propst Wilhelm von Mönchsroth und Hans von Ahelfingen dieselben Personen im württembergischen Umfeld als Vermittler für die Vermögensauseinandersetzung zwischen Abt und Konvent auf, die schon 1459 die Reformstatuten prüfen soll$\operatorname{ten}^{100}$. Die Umwandlung wurde dann am 2. April 1460 vollzogen $^{101}$, die kaiserliche Bestätigung erfolgte am 5. Dezember $1460^{102}$.

Aus diesen Vorgängen lassen sich meines Erachtens folgende Schlüsse zur Motivation der Beteiligten und ihrem Zusammenspiel ziehen: Graf Ulrich V. und Kardinal Peter handelten anscheinend in hoher Übereinstimmung, sei es zunächst bei der Einsetzung des Abts 1452 gegen den Willen des Konventes, sei es bei den Reformbestrebungen 1454. Eine Distanzierung zumindest von finanziellen Reformen in Ellwangen wird bei Kardinal Peter deutlich, als er 1457 in der Auseinandersetzung um den Dekan Ulrich von Hoppingen, dessen Sparungspläne auf Widerstand des Konvents stießen, letztlich zugunsten des ihm verwandtschaftlich verbundenen Georg vom Stein als Vermittler tätig wurde, und Georg vom Stein das Dekanat und damit die Führungsposition im Konvent erhielt. Der Reformversuch 1459 ging dann nicht mehr von Kardinal Peter aus ${ }^{103}$. Einig agierten beide dann wieder im Vollzug der Umwandlung. Denn Graf Ulrichs V. Mitwirkung wird über das Besetzungsrecht für die beiden Pfründen, das ihm die Bulle Papst Pius' II.

17. Januar 1460, einen Dispens zum Fleischgenuss während der Fastenzeit vom 17. Januar 1460 sowie das im Folgenden noch genauer zu besprechende Privileg betreffs die Gumbertuskirche in Ansbach vom 18. Januar 1460, vgl. Repertorium Germanicum Online, RG VIII 00076 (http://rg-online.de.dhi-roma.it/RG/8/76, abgerufen am 10.06.2016).

97 Vgl. Zeller, Die Umwandlung (wie Anm. 1) S. 16, S. 21.

98 Vgl. ebd., S. $338 \mathrm{f}$.

99 Vgl. ebd., S.344-347; hauptsächlicher Streitpunkt war die Neuverteilung der Ressourcen des Klosters zulasten des Abtes, da unter anderem die höhere Zahl von Vikarsstellen und bauliche Maßnahmen dies erforderten, vgl. ebd., S.344 f.

100 Vgl. ebd., S. 345.

101 Vgl. ebd., S. 347. Die Urkunden darüber und die Statuten des Stifts werden jedoch erst mehrere Monate später ausgestellt und dann rückdatiert; die noch ausstehende Beurkundung des Vorgangs verwendet Peter als Druckmittel gegenüber dem Konvent, vgl. ebd., S. 349 .

102 Ebd., S. 349 f.

103 Dagegen Stievermann, Das geistliche Fürstentum (wie Anm.51) S.41, der in den Reformvorhaben Ende der 1450er Jahre ein Engagement Peters und einen Rückzug Ulrichs sieht. 
zugestand, ja auch an der Beteiligung von Personen aus seinem Umfeld in den Verhandlungen um die Umwandlung deutlich. Dass er nicht mitsupplizierte, ist nicht ungewöhnlich, jedenfalls kirchenrechtlich nicht erforderlich. Möglicherweise wollte der sehr auf seine Eigenständigkeit bedachte Konvent bei diesem Vorgang keinen Einfluss seines Schirmers zulassen, aus dem dieser später hätte weitergehende Rechte ableiten können ${ }^{104}$.

Die Übereinstimmung zwischen Kardinal Peter und Graf Ulrich V. lässt sich auch aus einem weiteren Dokument erschließen, aus dem die Sichtweise der dritten Person deutlich wird, die an der Umwandlung beteiligt war: Markgraf Albrecht Achilles von Brandenburg. Das Dokument entstand nach der Bulle Pauls II. zur Annullierung der Umwandlung vom 18. Juni $1465^{105}$. Um den Papst umzustimmen, versuchte der Konvent, Unterstützungsschreiben von hochgestellten Personen zu gewinnen, darunter von Kaiser Friedrich III., der die Umwandlung als Oberherr im Dezember 1460 bestätigt hatte, und von Kardinal Peter, der sein Handeln beim Vollzug der Umwandlung verteidigte und die gegenüber dem vorherigen Zustand gottgefälligere Lebensweise und bessere Verrichtung des Gottesdienstes im Stift betonte ${ }^{106}$. Ein Schreiben Graf Ulrichs V. fehlt ${ }^{107}$.

Umso aufschlussreicher ist jedoch das Schreiben Markgraf Albrecht Achilles' von Brandenburg vom 5. August 1467 ${ }^{108}$ : Er schreibt, dass er bei Papst Pauls Vorgänger, Pius II., unter anderem die Genehmigung zur Umwandlung erreicht habe $^{109}$. Denn Kardinal Peter, Graf Ulrich V. und er hätten dies als eine gute und gottgefällige Tat angesehen ${ }^{110}$. Eine Annullierung würde alle drei kränken - insbe-

104 Darauf könnte hindeuten, dass in der Supplik der exemte und reichsunmittelbare Charakter des Klosters explizit hervorgehoben wird; der entsprechende Eintrag im Repertorium Germanicum lautet: Johannes abb. etc. mon. s. Viti in Elwangen o.s. Ben. August. Dioc. sed. ap. immed. subiecti cuius abb. semper princeps $R$. I. extitit m. supprimendi statum mon. et erig. in eccl. can. sec. c. reserv. Ulrico com. de Wirtenberg d. mon. protectori in temporal. iur. present. ad 2 preb. 14 ian. 1460; Repertorium Germanicum Online, RG VIII 02780 (http://rg-online.de.dhi-roma.it/RG/8/2780, abgerufen am 22.05.2016). - Ellwangen wahrte seine Stellung auch dadurch, dass die Schirmverträge mit Württemberg immer nur auf Zeit abgeschlossen wurden, vgl. SeILER (wie Anm. 7) S. 350.

105 Vgl. Zeller, Die Umwandlung (wie Anm. 1) S. 356; diese wurde jedoch nie umgesetzt, vgl. ebd., S. 356-361.

106 Vgl. ebd., S. 356-359; die Unterstützungsschreiben sind ebd., S. 285-288 abgedruckt.

107 Vgl. ebd., S. 357; Zeller vermutet, es sei nicht überliefert worden, SEILER (wie Anm. 7) S. 356 geht davon aus, dass es ein solches Schreiben nie gegeben habe, weil die Umwandlung als Niederlage der Reformpläne Graf Ulrichs anzusehen sei.

108 Vgl. Zeller, Die Umwandlung (wie Anm. 1) S. 357 f., Druck ebd., S. 285 f.

109 Cum preteritis temporibus ad requisicionem bone memorie Pii pape predecessoris S. $v$. uti obediens ad conventum Mantuanum venissem, inter alia a $S$. sua monasterium s. Viti in Elwangen Augusten. dioc. ex racionabilibus causis S. suam moventibus transfessi obtinui; ebd., S. 285.

110 Quam reverendissimus dominus cardinalis Augustensis loci diocesanus, Ulricus de Wirtenberg comes dicti opidi dominus et monasterii protector una mecum id bene dactum ac deifice gestum diiudicarunt [...]; ebd. 
sondere ihn, der so viel Arbeit und eine so anstrengende Reise zugunsten der Sache unternommen habe, dass er sie als die seine ansehe ${ }^{111}$. Er nennt also alle drei als einträchtig Zusammenwirkende, und sich geradezu als den spiritus rector, zumindest den, der den größten Einsatz erbracht habe.

Dieses Engagement war zweifelsohne erforderlich: Der Konvent hatte sich wohl in einer Zwangslage gesehen, sonst hätte er nicht den ungewissen - siehe den dann unterdrückten Passus im Konzept für den Prokurator - und teuren Weg der Umwandlung auf sich genommen. Es bedurfte geradezu eines so entschieden profilierten Reformers wie des Württembergers, um die Drohung der bevorstehenden Reform plausibel erscheinen zu lassen. Jedoch hatte der vom Konvent bestimmte Prokurator Georg vom Stein keine kuriale Erfahrung; ihn scheint lediglich außer seinem Amt die Verwandtschaft zu Kardinal Peter für diese Aufgabe qualifiziert zu haben. Wenn aber jemand einer so ungewöhnlichen Forderung beim Papst persönlich Gehör verschaffen konnte, dann war das der dem Papst gut bekannte Markgraf Albrecht, nicht Georg vom Stein.

Das aufgrund der Vidimierung der Bulle vermutete persönliche Erscheinen Markgraf Albrechts in Ellwangen, um die Bulle und damit die Lösung des dringendsten Problems des Konvents zu präsentieren, kann man sich als eine Inszenierung von großer Wirkung auf die Mönche und mittelbar deren Familien, zu denen die Nachricht kam, vorstellen. Konstantin Langmair hat vor kurzem aktuelle Reflexionen über politische Handlungsmuster spätmittelalterlicher Fürsten zusammengefasst ${ }^{112}$ : Er weist auf die zentrale Wichtigkeit der "personalen Komponente “113 und „situativ angewandter Techniken der Macht" ${ }^{114}$ hin. Es sei darum gegangen „Spielräume auszuloten, Zwangslagen auszunützen, Leerstellen zu besetzen“115, sowie „politische Handlungsmöglichkeiten innerhalb der vorgegebenen Strukturen auszumachen und Anhänger bzw. potentielle Sympathisanten durch politisch inszeniertes Handeln (,Signalhandeln') zu gewinnen. "116 Mir scheint diese Szene ein Beispiel für Signalhandeln mit hoher Aussagekraft zu sein, dessen Notwendigkeit aus dem im Folgenden referierten politischen Kontext deutlich werden soll.

111 In quibus S. v. [...] verum diocesanum, Ulricum de Wirtenberg comitem et me lederet, qui hoc molestiarum maximo labore et gravi itinere impetravi, ut rem ipsam propriam meam reputo; ebd., S. 286.

112 Vgl. Konstantin Moritz Langmaier, Rezension von: Christof Paulus, Machtfelder. Die Politik Herzog Albrechts IV. von Bayern (1447/1465-1508) zwischen Territorium, Dynastie und Reich, Köln/Weimar/Wien 2015, in: sehepunkte 16 (2016) Nr.3 [15.03.2016] (www.sehepunkte.de/2016/03/28188.html, abgerufen am 20.05.2016).

113 Ebd.

114 Ebd.

115 Paulus (wie Anm. I 2) S. 622, zitiert nach Langmaier (wie Anm. 112).

116 Langmaier (wie Anm. 112). 


\section{Die Vor- und Anfangsphase des Fürstenkriegs}

Gegen Ende der 1450er Jahre bildeten sich im Reich zwei Koalitionen heraus ${ }^{117}$ : Auf der obersten Reichsebene bestand der Konflikt zwischen Kaiser Friedrich III. von Habsburg und seinem Bruder, Herzog Albrecht VI. von Österreich ${ }^{118}$; ihnen folgend bildeten sich auf der Ebene der Fürsten und Grafen im Verlauf des Jahres 1458 zwei Bündnisblöcke ${ }^{119}$ : Einerseits, verbunden mit dem Kaiser, der sogenannte Mergentheimer Bund ${ }^{120}$ zwischen Markgraf Albrecht Achilles von Brandenburg und Graf Ulrich V. von Württemberg als ersten, denen sich unter anderem der Erzbischof von Mainz und Graf Ludwig von Veldenz anschlossen ${ }^{121}$. Andererseits eine von den Wittelsbachern dominierte Koalition zwischen dem Pfalzgrafen Friedrich, Herzog Ludwig von Bayern-Landshut, Markgraf Karl von Baden und den Bischöfen von Würzburg, Bamberg und Augsburg ${ }^{122}$.

Aus der Reihe von Konfliktfeldern sollen nur wenige Punkte genannt werden: Albrecht ging es als treuem Parteigänger der Habsburger vor allem darum, eine Annäherung des Pfälzers und des Wittelsbachers zu verhindern, was ihm jedoch nicht gelang ${ }^{123}$. Graf Ulrich V. von Württemberg stand mit dem Pfalzgrafen Friedrich unter anderem im Konflikt um die Vormundschaft über Ulrichs Neffen in Württemberg-Urach, dem seinen Verwandten unterstehenden württembergischen Territorium seit der Landesteilung $1442^{124}$. Zunächst hatte Pfalzgraf Friedrich einen zunehmend größeren Einfluss auf die Uracher Räte errungen, die sich von Graf Ulrich emanzipieren wollten ${ }^{125}$. Ulrich hatte auch aus einer vergeblichen Politik der Annäherung an Herzog Ludwig den Reichen von Bayern-Landshut Schaden genommen ${ }^{126} .1457$ bewahrten nur ein Eingreifen Markgraf Albrechts und dessen Verhandlungsgeschick Graf Ulrich V. vor einem drohenden Krieg mit dem Pfalzgrafen ${ }^{127}$.

117 Im Folgenden kann lediglich die Vor- und Anfangsphase (ca. 1458-1460) des Fürstenoder Reichskriegs (1458-1463) in Grundzügen beschrieben werden; die Darstellung folgt vor allem Thomas FrITZ, Ulrich der Vielgeliebte (1441-1480). Ein Württemberger im Herbst des Mittelalters. Zur Geschichte der württembergischen Politik im Spannungsfeld zwischen Hausmacht, Region und Reich (Schriften zur südwestdeutschen Landeskunde, Bd. 25), Leinfelden-Echterdingen 1999.

118 Vgl. ebd., S.7.

119 Vgl. ebd., S. 175 f.

120 Es handelte sich um das Wiederaufleben eines älteren Bündnisses, vgl. ebd., S.179f.

121 Vgl. ebd., S. 182.

122 Vgl. Elke Tкосz, Markgraf Albrecht Achilles und das Hochstift Bamberg. Ambivalente Beziehungen zwischen den beiden Fürstentümern, in: Kurfürst Albrecht Achilles (wie Anm. 73) S.443-462, hier S. 453.

123 Vgl. Fritz (wie Anm. 117) S.150, S. 190.

124 Vgl. ebd., S. $151-154$.

125 Vgl. ebd., S. $121-126$.

126 Vgl. ebd., S. $126-134$, S. 168 f.

127 Vgl. ebd., S. 140-146 zur Entwicklung der Krise; S. 146-150 zur Lösung durch Albrecht. 
Das überlegene politische Geschick Markgraf Albrechts zeigt sich auch in einigen anderen Auseinandersetzungen, in denen er Graf Ulrich V. im Vorfeld des Kriegsausbruchs half ${ }^{128}$, in mindestens einem Fall (Jost von Zollern) mit der Hoffnung auf Unterstützung durch den Betreffenden im Kriegsfall aufgrund des ihm gewährten Entgegenkommens ${ }^{129}$. In der Folge lehnte sich Graf Ulrich V. eng an Markgraf Albrecht an ${ }^{130}$. Als Graf Ulrichs V. älterer Neffe Ludwig starb, konnte er den Einfluss der Uracher Räte ausschalten und als alleiniger Vormund seines jüngeren Neffen Eberhard agieren ${ }^{131}$.

Die Spannungen wuchsen jedoch im Verlauf des Jahres 1458. Sie fanden ihren Ausdruck unter anderem in der erfolgreichen Belagerung der Burg Widdern im Juni $1458^{132}$, wobei die Koalition von Markgraf Albrecht und Graf Ulrich V. ihre Stärke demonstrierte ${ }^{133}$. Die Eroberung der Reichsstadt Donauwörth durch Herzog Ludwig von Bayern-Landshut im Oktober 1458 sollte dann zum Auslöser des Kriegs werden ${ }^{134}$. Die Bündnisbildung wurde in der Festkultur zelebriert: Parallel feierten beide Parteien Weihnachten 1458 in Aschaffenburg und Heidelberg ${ }^{135}$.

Das Jahr 1459 stand einerseits im Zeichen der Kriegsvorbereitung und andererseits von Versuchen, den Krieg noch abzuwenden ${ }^{136}$. Zu den Vorbereitungen zum Krieg ist zu zählen, dass Graf Ulrich V. versuchte, mehrere sich schon länger hinziehende Auseinandersetzungen zu einem zumindest vorläufigen Abschluss zu bringen, vermutlich um sich auf die bevorstehende größere Auseinandersetzung konzentrieren zu können ${ }^{137}$. Weiterhin nahm er im Juni 1459 Hans von Rechberg, einen erfahrenden Fehdeunternehmer mit engen Verbindungen zu Markgraf Albrecht, in seine Dienste ${ }^{138}$. Zugleich sind über das Jahr hinweg und bis in den Beginn der Kampfhandlungen zu Anfang des Jahres 1460 verschiedene letztlich erfolglose Versuche der Vermittlung und Beilegung der Konflikte zu beobachten, auch auf Initiative Papst Pius' II. ${ }^{139}$. An mehreren davon war Kardinal Peter von Schaumberg beteiligt ${ }^{140}$.

\footnotetext{
128 Vgl. ebd., S. $154-162$.

129 Vgl. ebd., S. 162 f.; Jost von Zollern verhält sich später neutral, vgl. ebd., S. 169.

130 Vgl. ebd., S. 150, S. 168.

131 Vgl. ebd., S. $169-174$.

132 Widdern war eine mehrheitlich von pfälzischen Dienstmannen gehaltene Ganerbenburg und Ausgangspunkt für Fehden gegen Ulrich, vgl. ebd., S. 167 f.

133 Vgl. ebd., S. $180-185$.

134 Vgl. ebd., S. 188-190.

135 Vgl. ebd., S. 191.

136 Vgl. ebd., S. 192 f.

137 Vgl. ebd., S. 194.

138 Vgl. Niklas Konzen, Aller Welt Feind. Fehdenetzwerke um Hans von Rechberg $(†$ 1464) im Kontext der südwestdeutschen Territorienbildung (VKgL B 194), Stuttgart 2014, S. 200.

139 Vgl. Fritz (wie Anm. 117) S. 197-199.

140 Vgl. Zoepfl (wie Anm.77) S. 400 f.
} 
Im Juni 1459 verkündete Kaiser Friedrich III. den Reichskrieg gegen Herzog Ludwig wegen der Eroberung Donauwörths; Markgraf Albrecht von Brandenburg und der Sachsenherzog wurden zu Reichshauptleuten ernannt ${ }^{141}$. Graf Ulrichs V. Situation verschlechterte sich gegen Jahresende 1459, als sich sein Neffe Eberhard im jüngsten dafür möglichen Alter, nach seinem 14. Geburtstag am 11. Dezember 1459, gegen den Willen seines Onkels als mündig erklären ließ und die Landschaft Urach ihm als dem rechtmäßigen Herrn folgte; er trat am 14. Dezember seine Herrschaft an ${ }^{142}$. Mit Brief vom 19. Dezember 1459 lenkte Graf Ulrich V. ein und erkannte ihn an ${ }^{143}$.

$\mathrm{Zu}$ Weihnachten 1459 wurde in Aschaffenburg zwischen den Verbündeten um Markgraf Albrecht und Graf Ulrich V. ein neuer Angriffsplan verabredet, datiert vom 28. Dezember 1459144. In dieser Zeit muss Markgraf Albrecht auch in den oben dargestellten Angelegenheiten und um der dringenden Bitte des Papstes nachzukommen nach Mantua abgereist $\operatorname{sein}^{145}$. Im Februar 1460 begannen die Kampfhandlungen ${ }^{146}$.

Die Umwandlung des Klosters Ellwangen steht also in enger zeitlicher Verknüpfung zum Fürstenkrieg: Sie wird mitten in der Phase der Kriegsvorbereitung, geradezu unmittelbar vor dessen Ausbruch, plötzlich angestrebt, ungewöhnlich schnell erreicht und während der ersten Phase des Krieges umgesetzt. Inwieweit dieser zeitlichen Korrelation auch eine Kausalbeziehung zugrunde liegen könnte, soll nun im Folgenden erörtert werden.

\section{Abschließende Überlegungen zu den Motiven der an der Umwandlung Ellwangens beteiligten Parteien}

Zuerst ist der Konvent zu nennen: Er dürfte wohl im Oktober 1459 beim letzten Reformversuch Graf Ulrichs V., der sich ja im Frühjahr 1459 eine Generalvollmacht zur Reform der in seinem Machtbereich liegenden Klöster hatte ausstellen lassen, den letzten Anlass gesehen haben, nun den Wechsel seiner Rechtsform anzustreben. Als führende Figur ist der Dekan des Konvents, Georg vom Stein,

\footnotetext{
141 Vgl. Fritz (wie Anm. 117) S. 194.

142 Vgl. ebd., S. 200-206.

143 Vgl. ebd., S. 208.

144 Vgl. ebd., S. 210.
}

145 Das bei MüLler zusammengestellte Itinerar nennt den 21. Dezember als Tag des Aufbruchs nach Mantua, am 23. Dezember urkundete Markgraf Albrecht in Kempten, vgl. Itinerar Markgraf Albrecht Achilles' 1414-1486, in: Kurfürst Albrecht Achilles (wie Anm. 73) S. 565-602, hier S. 571. Möglicherweise wurde der Plan schon früher verabredet und erst später beurkundet; für den 5. Dezember verzeichnet das Itinerar einen Aufenthalt Markgraf Albrechts in Mergentheim, vgl. ebd. Dem Widerspruch zu den Angaben bei Fritz konnte für die vorliegende Studie nicht weiter nachgegangen werden.

146 Vgl. Fritz (wie Anm. 117) S.210-213. 
anzusehen. Da er mit Kardinal Peter vom Schaumberg verwandt war und diesem sein Amt verdankte, dürfte er den Kontakt zu ihm aufgenommen haben.

Kardinal Peter von Schaumberg ist zwar einerseits als Vertreter der Klosterreform bekannt, bei genauerer Betrachtung zeichnet er sich jedoch durch eine sehr differenzierte Klosterpolitik aus: Neben Klosterreformen stehen die Aufhebungen mehrerer Klöster, die zum Teil zugunsten seiner Mensa oder seiner Weihbischöfe erfolgten ${ }^{147}$. Seine pragmatische Haltung zeigte sich bereits 1454, als er dem Ellwanger Konvent eine vergleichsweise milde Reform auferlegen wollte. Hierzu könnte ihn das Negativbeispiel des Bamberger Kloster Michelsberg, das sich gerade in heftigen Auseinandersetzungen mit dem Bischof vom Bamberg befand, die erst einige Jahre später mit der Reform des Klosters endeten, bewogen haben ${ }^{148}$. Diesen Realismus legte er später auch in der Prämisse zutage, in Ellwangen lieber ein lebensfähiges Stift einzurichten, als weitere fruchtlose Reformversuche mitzu$\operatorname{tragen}^{149}$.

Dazu traten ein starkes persönliches Moment durch seine Verwandtschaft zum Dekan des Klosters und seine Verbindung zu dessen Abt, der ihm ja sein Amt verdankte, sowie ein kirchenpolitisches: Denn er pflegte immer ein gutes Verhältnis zum Augsburger Domkapitel ${ }^{150}$, dem zu dieser Zeit auch Angehörige der Hürnheim, vom Stein und Schenkenstein angehörten ${ }^{151}$, also Familien, die zugleich Angehörige im Kloster hatten ${ }^{152}$. Nicht zuletzt scheint seine zwischen verschiedenen Interessen ausgleichende Haltung vor allem auch seinem Charakter zu entspringen, da er seit Jahrzehnten vor allem als Vermittler und Schlichter tätig war ${ }^{153}$. Dies galt auch für die aktuellen Auseinandersetzungen, in denen er zwar auf der Gegenseite von Markgraf Albrecht und Graf Ulrich V. stand, mit diesen aber in Verhandlungen begriffen gewesen war und dies wohl auch für die Zukunft erwarten konnte ${ }^{154}$. Hierbei konnte ein Entgegenkommen in der Ellwanger Angelegenheit einen diplomatischen Vorteil bedeuten. Jedoch bedeutete sein Eingehen auf den Konvent keine schrankenlose Nachgiebigkeit: Sein autoritatives Auftreten diesem gegenüber in den Auseinandersetzungen, die der Gründung des Stifts vorausgingen, zeigte ihn nicht schwach, sondern als Gestalter der neuen Situation.

\footnotetext{
147 Vgl. Zoepfl (wie Anm. 77) S. $434 \mathrm{f}$.

148 Vgl. ebd., S. 340.

149 Vgl. ebd., S. 438 f.

150 Vgl. ebd., S. 447-450.
}

151 Es handelt sich um Balthasar von Hürnheim, vgl. Haemmerle (wie Anm. 79) S. 98, Nr.474; Albrecht vom Stein, vgl. ebd., S.160, Nr.797; Konrad Schenk von Schenkenstein, vgl. ebd., S.152, Nr.754. Auch der ehemaligen Scholaster des Domkapitels und letzte Abt des Klosters, Johann von Hürnheim, könnte noch persönliche Beziehungen zu seinen ehemaligen Mitkapitularen unterhalten haben.

152 Vgl. Zeller, Die Umwandlung (wie Anm. 1) S. $351 \mathrm{f}$.

153 Vgl. Zoepfl (wie Anm. 77) S. 425.

154 Dies sollte auch eintreten, vgl. ebd., S. $401 \mathrm{f}$. 
Markgraf Albrecht Achilles von Brandenburgs prononcierte Unterstützung der Umwandlung eines adligen Konvents fügt sich nicht nur konsequent in seine allgemeine Politik gegenüber Adligen, vor allem dem Adel Frankens, ein, sondern zeigt sich im konkreten Fall auch funktional als Strategie zur Generierung politischer Unterstützung im Vorfeld eines Krieges, bei dem er seiner Gegenpartei finanziell unterlegen und daher vor allem auf sein persönliches Prestige angewiesen war, um Gefolgschaft oder zumindest eine wohlwollende Neutralität des regionalen Niederadels zu erreichen ${ }^{155}$. Können die Notwendigkeit guter Beziehungen zum Niederadel und das Streben nach dessen Unterstützung schon allgemein als Strukturkonstanten fürstlicher Herrschaft gelten ${ }^{156}$, so setzte Markgraf Albrecht hier noch einen besonderen Schwerpunkt seiner Politik, deren Zweck Hillay Zmora wie folgt zusammenfasst: „Um eine Identifikation des Adels mit dem markgräflichen Haus zu bewirken, präsentierte sich Albrecht konsequent als ,Liebhaber ${ }^{6}$ des fränkischen Adels“ ${ }^{157}$ - und auch über den Raum Franken hinaus ${ }^{158}$ _ „als Gönner des Adels und Liebhaber von dessen Freiheit" ${ }^{\text {159 }}$. Als Mittel, um Adlige an sich zu ziehen, dienten unter anderem eine aufwändige Hofhaltung ${ }^{160}$, die Abhaltung von Turnieren ${ }^{161}$ und die Selbstrepräsentation als Kriegsherr und Vorbild ritterlicher Tugenden ${ }^{162}$.

Diese weltlichen Aktivitäten wurden durch seine Ambitionen auf geistlichem Gebiet flankiert und ergänzt ${ }^{163}$. Als Maßnahme mit starker Ausstrahlung erwies sich die Einrichtung des fränkischen Zweigs des Schwanenordens ${ }^{164}$. Die dafür erforderliche Bulle, die die Privilegien der Marienkirche in Brandenburg auf die Georgskapelle in der Stiftskirche St. Gumbertus in Ansbach ausdehnte, wurde am 16. Januar 1460 ausgestellt ${ }^{165}$, also nur wenige Tage nach der Umwandlungsbulle für Ellwangen vom 14. Januar $1460^{166}$. Der Schwanenorden diente in der Folgezeit als „Kristallisationspunkt des fränkischen Adels“167: „Seit Errichtung des fränki-

155 Vgl. Uwe Tresp, „Deutscher Achilles“ und „Meister geordneter Heerfahrt“. Markgraf Albrecht Achilles von Brandenburg als Kriegsherr, in: Kurfürst Albrecht Achilles (wie Anm. 73) S. 487-502, hier S. 495.

156 Vgl. Zmora (wie Anm. 73) S. 236-238.

157 Ebd., S. 238.

158 Vgl. Markus FrankL, Der Schwanenorden unter Markgraf Albrecht Achilles, in: Kurfürst Albrecht Achilles (wie Anm. 73) S. 249-264, hier S. 254.

$159 \mathrm{Vgl}$. Zmora (wie Anm. 73) S.238.

160 Vgl. ebd., S. 239, weitere Mittel vgl. ebd., S. 240.

161 Vgl. FrankL (wie Anm. 158) S. 256.

162 Vgl. Tresp (wie Anm. 155) S. 495.

163 Vgl. FrankL (wie Anm. 158) S. 256.

164 Vgl. ebd., S. 253, S. 256.

165 Vgl. ebd., S. 252. Die Datierung widerspricht derjenigen des Repertorium Germanicum, das die Bulle für die Gumbertuskirche zwei Tage später ansetzt, vgl. Anm. 95.

166 Vgl. Anm.6.

167 Frankl (wie Anm.158) S. 256. 
schen Zweigs 1459 lassen sich zahlreiche Schwanenordensmitglieder in Aufgebotslisten der Zollern wie z.B. im Fürstenkrieg (1458-1463) oder bei Turnieren nachweisen. " 168 In den überlieferten Mitgliederlisten dieser Jahre finden sich alle Familien, die auch mit Mitgliedern im Ellwanger Konvent vertreten waren ${ }^{169}$. Die Unterstützung der Umwandlung Ellwangens lässt sich daher als parallele Form „ideeller Mobilisierung“ des Niederadels auffassen.

Das Verhältnis Markgraf Albrechts zu Graf Ulrich V. war ab 1458 durch eine sehr enge Verbundenheit gekennzeichnet, wobei Markgraf Albrecht eindeutig eine Führungsposition innehatte. Schon zuvor war Markgraf Albrecht im Verhältnis zu Graf Ulrich V. eindeutig als „Seniorpartner“" wahrnehmbar, wie sich in der mehrfachen, plötzlich gewährten Unterstützung in auftretenden Schwierigkeiten ab 1457 zeigte. Ende 1459 nun war Graf Ulrich V. - ganz abgesehen von der Kriegsgefahr - in einer doppelten Krisensituation: Einerseits durch den Konflikt mit seinem Neffen Eberhard, andererseits vermutlich durch den Konflikt über die Reform in Ellwangen. In Bezug auf den Konvent entsprach Albrechts Auftreten seinem vorherigen Handeln zugunsten Graf Ulrichs V. in problematischen Situationen: Wieder neutralisierte er einen „Krisenherd“.

Hierin folgte ihm Graf Ulrich V., indem er in der existentiell bedrohlichen Situation Ende 1459 seine Präferenz als überzeugter Vertreter der Klosterreform zurückstellte, und, wie auch mit der Akzeptanz von Eberhards Mündigkeit, zeigte, dass er in seinen Überzeugungen nicht festgelegt war, sondern flexibel und situationsangepasst agieren konnte.

Zudem kann zwischen beiden geradezu eine Form von Arbeitsteilung angenommen werden, von der aber letztlich beide profitierten: Wenn Markgraf Albrecht als Befürworter der Umwandlung Ellwangens erschien, konnte seine Aktivität als generöse Geste gelten, bei Graf Ulrich V. hätte dies als Schwäche gegenüber dem Konvent ausgelegt werden können. Daher scheint es plausibel, das anfangs konstatierte „Schweigen" Graf Ulrichs V. so zu interpretieren, dass er - jedoch in seinem Sinne - reden und handeln ließ.

Papst Pius' II. übergeordnetes politisches Ziel hingegen war - erst wenige Jahre nach dem Fall von Konstantinopel - der geplante Kreuzzug gegen die Türken. Aus dieser Motivation heraus gewährte er einer Reihe von Fürsten Privilegien, in die

\section{Ebd.}

169 Vgl. Ritterorden und Adelsgesellschaften im spätmittelalterlichen Deutschland (Kieler Werkstücke, Reihe D: Beiträge zur europäischen Geschichte des späten Mittealters, Bd.1), hg. von Holger Kruse/Werner Paravicini/Andreas Ranft, Frankfurt am Main u.a. 1991, S. 336-343. Die dort publizierte Liste ist aus Mitgliederlisten des Schwanenordens aus den Jahren 1443, 1455 und 1464/1465 zusammengestellt. Damit wurde - mit dem oben genannten Ergebnis - die Liste der Konventsmitglieder vor der Umwandlung bei Zeller (vgl. Zeller, Die Umwandlung (wie Anm.1) S. 351 f.) verglichen, wo die folgenden Namen genannt werden: von Hürnheim, von Westerstetten, von Berlichingen, von Neuneck, Schenk von Schenkenstein, von Hausen, von Wirsberg, von Hoppingen, von Rechberg. 
sich auch die Gunsterweise für Markgraf Albrecht einordnen lassen, und förderte den Erhalt des Friedens im Reich; auch hierfür sah er in Markgraf Albrecht wohl eine Schlüsselfigur. Zu Beginn des Jahres 1460 begann Papst Pius II. eine letzte große Friedensinitiative durch Entsendung eines päpstlichen Legaten ${ }^{170}$. In diesem Zusammenhang scheint es plausibel, dass er mit der Genehmigung der Umwandlung sowohl Markgraf Albrecht als auch Kardinal Peter zum Gefallen handelte.

In Variation und Antwort auf das anfänglich zitierte Diktum Dieter Stievermanns ${ }^{171}$ : Ein Papst mit weitreichenden politischen Zielen, die den Status von Ellwangen als vernachlässigbar erscheinen ließen, ein Bischof in verwandtschaftlicher Verantwortung und pragmatischer Einschätzung des Erreichbaren, ein Schirmer in einer vielfachen politischen Krisensituation und sein engster politischer Verbündeter, der mit einer adelsfreundlichen Politik auf geistlichem Terrain eine bessere politische Basis für einen bevorstehenden Kriegszug schaffen wollte und dies durch demonstratives Handeln zugunsten der Umwandlung des Klosters propagierte - in diesem vielschichtigen und vielfach ineinandergreifenden politischen Kräftefeld wurde die Ellwanger Säkularisation überhaupt erst möglich.

170 Vgl. Fritz (wie Anm. 117) S. 212

171 Vgl. Anm. 10. 